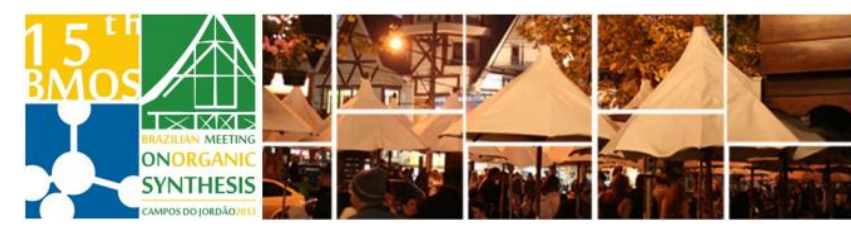

\title{
Synthesis of fluorescent symmetric bis-imidazolium-BTD salts
}

\author{
Virginia S. Souza, Gabriela I. Matiello, Patrícia C. Ferreira, Günter Ebeling and \\ Jairton Dupont ${ }^{\star}$
}

Laboratory of Molecular Catalysis, Institute of Chemistry, UFRGS, Av. Bento Gonçalves 9500, Agronomia,

\author{
91501-970, Porto Alegre-RS, Brazil. \\ *jairton.dupont@ufrgs.br
}

Keywords: Benzothiadiazole, Imidazolium salts and luminescence.

\section{INTRODUCTION}

Benzothiadiazole (BTD) is one of the most important classes of conjugated systems because of their photophysical properties such as high extinction coefficient, intense fluorescence, and large Stokes shift. These features make them useful in a variety of applications such as optical materials and chemosensors. Fluorescent BTD derivatives are used in practical applications, including their utility as laser dyes, emitters in light-emitting diodes, photoconductors, optical data storage, and optical switches. Imidazolium salts have advantageous physicochemical properties, which can be modulated by the use of different cations and anions. In this work we are interested to explore a straightforward synthesis of a new class of luminescent imidazolum salts derived from imidazole-BTD as starting material.

\section{RESULTS AND DISCUSSION}

4,7-Dibromo-2,1,3-benzothiadiazole (1) is a common compound used for the synthesis of benzothiadiazole with m-extended photoluminescent properties, and for this work it was prepared according to a known procedure reported earlier. ${ }^{1}$ The reaction of compound 1 and imidazole at $150{ }^{\circ} \mathrm{C}$ afforded the coupling product 2 in 48 h $(82 \%$ yield; Scheme 1), which was employed as starting material for the synthesis of compounds 3,4 and 5 .
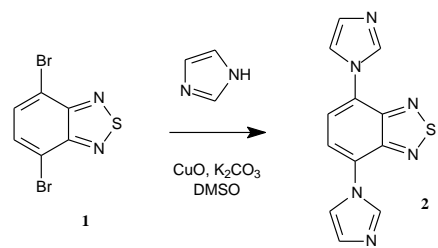

Scheme 1. Synthesis of 4,7-bis-imidazolium-2,1,3benzothiadiazole (2).

In order to prepare the imidazolium salt $\mathbf{3}$, the alkylation procedure was performed by reacting compound $\mathbf{2}$ and methyl iodide in acetonitrile at reflux temperature giving $87 \%$ yield after $24 \mathrm{~h}$ (Scheme 2). The dicationic salt 4 was synthesized by bubbling dried $\mathrm{HCl}$ gas into a hot solution of compound $\mathbf{2}$ in methanol. In this case, a simultaneous precipitation of salt $\mathbf{4}$ can be observed with an isolated yield of $70 \%$. For the preparation of bis-imidazolium salt $\mathbf{5}$, the bis-imidazole-BTD 2 was reacted in the presence of chloro-acetic acid under reflux condition in acetonitrile during 4 days (38\% yield; Scheme 2).

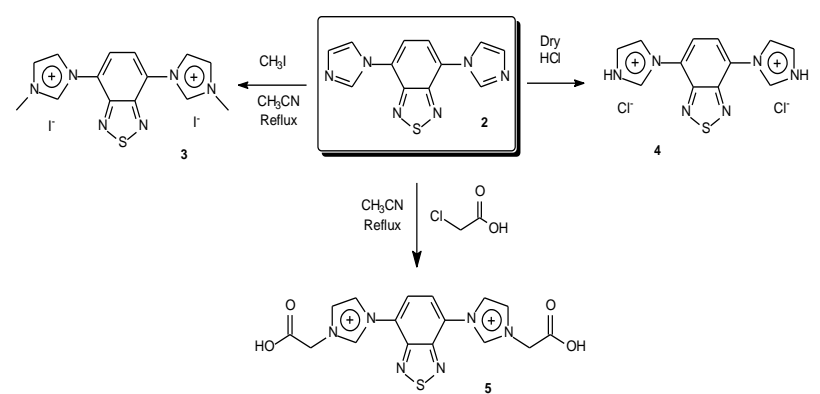

Scheme 2. Synthesis of dicationic imidazolium salts 3-5.

The dicationic imidazolium salts 3-5 were characterized using ${ }^{1} \mathrm{H} /{ }^{13} \mathrm{C}$ NMR, FTIR, UV-vis spectroscopy. The photophysical properties of these salts are being evaluated in our research group. It is expected that these salts can be used as alternative metal-free dyes for solar cell application ${ }^{2}$ as well as fluorescent ligands for cell imaging ${ }^{3}$.

\section{CONCLUSION}

In the present work is described a simple method to synthesize a new class of luminescent symmetric bis-imidazolium-BTD salts (3-5). In general, high isolated yields can be obtained after the alkylation step of bis-imidazole-BTD 2. Moreover, it is expected that the dicationic imidazolium salts 3-5 possess potential application in solar cells and as biological markers.

\section{ACKNOWLEDGEMENTS}

The authors wish to thanks CNPq and CAPES for financial support.

\section{REFERENCES}

${ }^{1}$ Dupont, J.; Neto, B. A. D.; Lapis, A. A. M.; Júnior, E. N. S. Eur. J. Org.

Chem. 2013, 228-255.

${ }^{2}$ Bäuerle, P.; Mishra, A.; Fischer, M. K. R. Angew. Chem Int. Ed.2009, 48, 2474.

${ }^{3}$ Neto, B. A. D. et al. Inorg. Chem. 2013, DOI 10.1021/ic4017678.

$15^{\text {th }}$ Brazilian Meeting on Organic Synthesis - 15 $5^{\text {th }}$ BMOS - November 10-13, 2013 - Campos do Jordão, Brazil 